\title{
Editorial Message: Special Issue on Fuzzy Logic for Complex Systems
}

\author{
Yih-Guang Leu ${ }^{1}$
}

Published online: 14 September 2020

(C) Taiwan Fuzzy Systems Association 2020

In the design of complex systems, it is difficult to build precise models using uncertain and small data. As the number of sensors in the Internet of Things increases, a large amount of data can be generated. Although a large amount of data can be used to model a complex system, the process of building the complex model may lead to deviations in the output results due to uncertainties. These uncertainties may be the fuzziness and impreciseness of the real-world data. Fuzzy logic plays a pivotal role in reflecting the fuzziness. Therefore, incorporating fuzzy logic in the process may deal with the fuzziness and impreciseness of the real-world data. The objective of the special issue is to address some of the latest research for incorporating fuzzy logic in the process of building a complex model at the 2019 International Conference on Fuzzy Theory and Its Applications (iFUZZY 2019) held at Tamkang University, New Taipei City, Taiwan, on November 7-10, 2019. Papers submitted to the IJFS special issue were initially reviewed by the guest editor and accepted as the oral presentations. In accordance with the strict paper review procedure of IJFS, I invited six experts, including Prof. Shun-Feng Su (the current Editor-in-Chief of IJFS), Prof. Yo-Ping Huang, Prof. Hak-Keung Lam, Prof. Yih-Guang Leu, Prof. Jenq-Lang Wu, and Prof. SongShyong Chen as the reviewers of all the oral presentations in iFUZZY 2019. According to the review criterion on contributions and completeness, there are six papers to be selected. After the elaborative revisions according to the suggestions and comments of the reviewers, these six papers have finally been accepted for publication in the IJFS special issue on fuzzy logic for complex systems. The titles of these six papers in the special issue are as follows: Fuzzy Control for Chaotic Confliction Model (Published: 05 April 2020), Traffic Signal Control using Genetic Decomposed Fuzzy Systems (Published: 01 April 2020), Design of Kinematic Controller Based on Parameter Tuning by Fuzzy Inference System for Trajectory Tracking of Differential-Drive Mobile Robot (Published: 04 June 2020), Fuzzy Moderation and Moderated-Mediation Analysis (Published: 04 June 2020), Control the Diversity of Population with Mutation Strategy and Fuzzy Inference System for Differential Evolution Algorithm (Published: 19 March 2020), and Interval Fuzzy c-Regression Models with Competitive Agglomeration for Symbolic IntervalValued Data (Published: 05 March 2020). Finally, I would like to acknowledge the reviewers and all the contributors to this special issue.

Guest Editor, iFUZZY 2019 IJFS Special Issue on Fuzzy Logic for Complex Systems.
Yih-Guang Leu

leuyk@ntnu.edu.tw

1 Department of Electrical Engineering, National Taiwan Normal University, Taipei, Taiwan 
Yih-Guang Leu (M'09) received the M.S. and Ph.D. degrees in electrical engineering from the National Taiwan University of Science and Technology, Taipei, Taiwan, in 1995 and 1999, respectively., From 1999 to 2006, he was an Associate Professor with the Department of Electronics Engineering, Hwa Hsia College of Technology and Commerce, Taipei. In 2005, he was an Associate
Professor and a Chairman of the Department of Electronics Engineering, Hwa Hsia Institute of Technology. He is currently a Professor with the Department of Electrical Engineering, National Taiwan Normal University, Taipei. His current research interests and publications are in the areas of fuzzy logic control, robust adaptive control, machine learning, and neural networks. 